Expert Rev Endocrinol Metab. 2009 September 1; 4(5): 435-442. doi:10.1586/eem.09.27.

\title{
Tumor-induced osteomalacia
}

\author{
Emily G Farrow and \\ Department of Medical \& Molecular Genetics, Indiana University School of Medicine, Indianapolis, \\ IN, USA \\ Kenneth E White, PhD ${ }^{\dagger}$ \\ Department of Medical \& Molecular Genetics, Indiana University School of Medicine, 975 West \\ Walnut Street, IB130, Indianapolis, IN 46202, USA, Tel.: +1 317278 1775, Fax: +1 3172742293 \\ Kenneth E White: kenewhit@iupui.edu
}

\begin{abstract}
Tumor-induced osteomalacia (TIO) is an acquired disorder of isolated renal phosphate wasting associated with tumors, typically of mesenchymal origin. Patients with TIO share similar biochemical and skeletal phenotypes with patients who have autosomal dominant hypophosphatemic rickets (ADHR) and X-linked hypophosphatemia. The study of TIO introduced the idea of the existence of circulating factors, referred to as 'phosphatonins', produced by the tumor, which act upon the kidney to reduce phosphate reabsorption. Although several factors have been identified, the phosphatonin FGF-23, also identified as the causative factor in ADHR, is currently the best characterized of these factors relative to phosphate handling. This review describes the importance of TIO in understanding phosphate homeostasis in the context of new endocrine interactions between the skeleton and the kidney.
\end{abstract}

\section{Keywords}

FGF-23; fibroblast growth factor-23; FRP4; hypophosphatemia; MEPE; oncogenic osteomalacia

Tumor-induced osteomalacia (TIO), also referred to as oncogenic osteomalacia, is an acquired disorder of isolated renal phosphate wasting, associated with tumors that often have a mesenchymal origin [1]. The study of patients with TIO introduced the existence of possible circulating factors, referred to as 'phosphatonins', produced by the tumor, which act upon the renal proximal tubule (PT) to decrease phosphate reabsorption $[1,2]$. The phosphatonin theory is supported by the fact that complete surgical removal of the neoplasm results in rapid correction of the abnormal phosphate wasting [3].

\footnotetext{
$\dagger$ Author for correspondence: Department of Medical \& Molecular Genetics, Indiana University School of Medicine, 975 West Walnut Street, IB130, Indianapolis, IN 46202, USA, Tel.: +1 317278 1775, Fax: +1 317274 2293, kenewhit@iupui.edu.

Financial \& competing interests disclosure

Kenneth E White receives royalties for licensing the FGF-23 gene to Kyowa Hakko Kirin, Ltd. The authors would like to acknowledge support by NIH grant DK063934 (Kenneth E White), the Showalter Foundation, and the Indiana Genomics Initiative (INGEN) of Indiana University, supported in part by the Lilly Endowment, Inc. The authors have no other relevant affiliations or financial involvement with any organization or entity with a financial interest in or financial conflict with the subject matter or materials discussed in the manuscript apart from those disclosed.

No writing assistance was utilized in the production of this manuscript.
} 


\section{Clinical presentation}

Tumor-induced osteomalacia is a rare disorder that can occur in children and adults [4]. These patients present with hypophosphatemia secondary to reduced renal phosphate reabsorption (as determined by the ratio of phosphorus tubule maximum to glomerular filtration rate), inappropriately low or normal $1,25(\mathrm{OH})_{2}$ vitamin $\mathrm{D}$ concentrations and elevated alkaline phosphatase levels [3]. The manifestations of TIO are similar to those of patients with autosomal dominant hypophosphatemic rickets (ADHR), X-linked hypophosphatemic rickets (XLH), and autosomal recessive hypophosphatemic rickets (ARHR). A common denominator of all of these conditions is the presence of elevated circulating FGF-23 concentrations (Table 1). TIO patients typically exhibit normal serum parathyroid hormone (PTH) and calcium levels, however with prolonged disease and treatment secondary hyperparathyroidism can develop $[5,6]$. Patient bone biopsies reveal osteomalacia, and clinical symptoms include onset of muscle weakness, fatigue and bone pain, especially in the ankles, legs, hips and back $[3,7,8]$. Insufficiency fractures are common in patients and proximal muscle weakness may become severe enough that patients become wheelchair- or bed-bound [3]. Children may present with poor growth and deformities of the lower extremities [4]. Owing to the rare nature of the disease, as well as multiple other causes of hypophosphatemia, such as refeeding syndrome, respiratory alkalosis, alcohol abuse, malabsorption, hepatic failure and blood cancers such as lymphoma and leukemia, a clear diagnosis of TIO can be challenging. In some cases, it has also taken years to locate the tumor [9]. It is possible that a heritable cause of hypophosphatemia, such as XLH, ADHR, and ARHR, could be distinguished from TIO through genetic analysis of the genes that lead to these disorders (Table 1). Hereditary hypophosphatemic rickets with hypercalciuria is another disorder of hypophosphatemia, and is due to mutations in the Type IIc sodium-phosphate cotransporter (NPT2c) [10,11]. However, in contrast to other forms of hypophosphatemia, hereditary hypophosphatemic rickets with hypercalciuria is characterized by a normal physiological response to hypophosphatemia through elevated $1,25(\mathrm{OH})_{2}$ vitamin $\mathrm{D}$, as well as the hypercalciuria associated with increased intestinal calcium absorption [12]. Additional features of TIO that may help in diagnosis include lack of a family history of hypophosphatemia, relatively rapid onset of symptoms and a previously-documented normal serum phosphate concentration.

The current therapy for TIO, in addition to surgical removal of the TIO lesion, includes oral replacement of phosphorus in combination with high dose $1,25(\mathrm{OH})_{2}$ vitamin $\mathrm{D}$. This regimen 'treats' TIO by increasing serum phosphate concentrations and ameliorates much of the metabolic bone disease, but does not directly 'cure' the disorder by reversing the underlying molecular defects in kidney and in bone.

\section{Tumor characteristics}

The majority of tumors in TIO are small, slow growing and of mesenchymal origin [9]. These tumors may develop in bone or soft tissues, are often difficult to locate by standard x-ray and MRI, and can be problematic to remove. The tumors that cause TIO may also resemble common, benign lesions [13]. TIO lesions have been classified into four categories based on histology and include: phosphaturic mesenchymal tumor, mixed connective tissue type (PMTMCT; $~ 75 \%$ in this category), osteoblastoma-like tumors, nonossifying fibroma-like tumors, and ossifying fibroma-like tumors $[9,13]$. Tumor metastases have been observed, but these appear to be rare occurrences [9].

Due to the small size and often unusual locations of these tumors, detection is frequently challenging. Standard imaging techniques, such as x-ray, CT scan and MRI [14], can be used to detect tumors. However, other methods, such as ultrasonography, as well as labeling approaches, such as whole-body $99 \mathrm{mTc}$ sestamibi scanning [15] and body $201 \mathrm{Tl}$ scintigraphy 
[16] have been required for tumor localization. Reports have also demonstrated some successes with ${ }^{111}$ I-indiumpentetreotide scintigraphy $[17,18]$; however, a negative octreotide scan may not preclude a diagnosis of TIO, as not all tumors have surface somatostatin receptors [19]. More recently, targeted venous sampling followed by detection of differential serum FGF-23 concentrations using established FGF-23 ELISAs was reported to provide a narrower region for follow-up imaging procedures and biopsies [20-22]. F-18 FDG PET/CT has also been used in several cases, and relies on the principle of increased uptake of radiolabeled glucose by tumors with increased glucose metabolism or lesions with increased blood supply [23-25]. In another strategy, due to the resemblance of TIO tumors to normal, benign nodes, the 'Intact' FGF-23 ELISA has been adapted into a rapid detection format [26]. This methodology uses a lysate from the suspected lesion as the substrate for the ELISA during surgery, and has proven successful in confirming the production of FGF-23 as a biomarker in the suspected TIO neoplasm [26].

\section{Phosphatonins \& TIO}

Studies of TIO brought forth the hypothesis that the tumors produce circulating factors that act upon the kidney to decrease phosphate reabsorption [1,2]. The 'phosphatonin' theory is supported by the fact that surgical removal of the neoplasm results in rapid correction of the abnormal phosphate wasting. Supporting studies have demonstrated that TIO tumor extracts and conditioned media from TIO tumor cell cultures can inhibit phosphate transport in model PT cells [2], and implantation of TIO tumor tissue into nude mice results in increased urinary phosphate excretion [27]. Although not a heritable disorder, clinical studies of TIO in combination with genetic approaches and animal models have been useful in identifying the mechanisms associated with potential phosphatonins because of the similar phenotype shared between TIO patients and those with heritable hypophosphatemias (Table 1).

\section{FGF-23}

Recent advances in our understanding of disorders involving phosphate metabolism have shed light on the underlying mechanisms of potential phosphatonins that control phosphate homeostasis in normal and disordered states. FGF-23 is the best-characterized phosphatonin with regard to serum phosphate handling, and was identified as the gene responsible for ADHR through a positional cloning approach [28]. Full-length FGF-23 $(32 \mathrm{kD})$ is the biologically active form of the protein and is inactivated upon cleavage into 20 and $12 \mathrm{kDa}$ protein fragments. The N-terminal region of FGF-23 contains the FGF-homology domain, whereas the C-terminus comprises a unique 71-amino acid tail [29]. Intracellular cleavage of FGF-23 occurs at a subtilisin-like proprotein convertase site $\left(\mathrm{R}_{176} \mathrm{XXR}_{179} / \mathrm{S}\right)[28,29]$, which inactivates the protein. The human FGF-23 ADHR mutations R176Q, R179Q, and R179W destroy this site and stabilize the full-length active form of the protein $[28,30]$. In support of these genetic observations, when either full-length FGF-23, the N-terminal fragment, or the C-terminal fragment are injected in vivo, only the intact hormone causes a reduction in serum phosphate concentrations [29]. Although FGF-23 mRNA can be detected at low levels in many tissues, this hormone is predominantly produced in bone [28]. FGF-23 is normally expressed by osteoblasts, osteocytes, flattened bone lining cells, and osteoprogenitor cells [31].

Serum FGF-23 concentrations are elevated in patients with TIO $[32,33]$ and tumors that cause TIO typically overexpress FGF-23 mRNA [34]. To determine if FGF-23 could be involved in TIO as a phosphatonin, we previously tested mRNA from five TIO tumors as well as several control tissues using northern blot for the presence of FGF-23 transcripts, and determined that FGF-23 mRNA was highly expressed in all tumors tested [34]. Furthermore, FGF-23 was present in a tumor lysate by Western blot analyses using an anti-FGF-23 antibody [34]. Surgical 
resection of the tumor results in rapid decreases in serum FGF-23 as determined by both a 'Cterminal' FGF-23 ELISA [32] or an 'Intact' FGF-23 ELISA [33].

In an independent approach to identifying FGF-23, RNA was isolated from a TIO tumor, and transcripts were identified as over-expressed by differential selection compared with normal bone [35]. The highly expressed transcripts were stably expressed in Chinese hamster ovary cells, which were then injected into nude mice to form tumor masses [35]. The cells that produced FGF-23 gave rise to the TIO phenotype in vivo by causing hypophosphatemia, elevated alkaline phosphatase and inappropriately low $1,25(\mathrm{OH})_{2}$ vitamin D concentrations [35]. In addition, the mice that received FGF-23-expressing cells also showed growth retardation, kyphosis and osteomalacia, similar to XLH and ADHR patients. Furthermore, these investigators observed marked decreases in the renal vitamin D 1- $\alpha$-hydroxylase mRNA. Both the biochemical and metabolic bone profiles of the experimental animals were parallel to those observed in patients with TIO and ADHR [35]. These experiments provided evidence that FGF-23 was a phosphaturic substance and had potent effects on enzymes involved in vitamin D metabolism, and that increased circulating FGF-23 concentrations were consistent with the idea that FGF-23 was, at least in part, responsible for the TIO phenotype. In additional studies, serial analyses of gene expresion indicated that there was increased expression of FGF-23 mRNA in a majority of TIO assessed tumors [36], which supports immunohistochemical data demonstrating that FGF-23 protein was detectable in a majority of TIO tumor samples [13,37].

Similar to PTH, FGF-23 functions to reduce renal phosphate reabsorption in the PT by downregulating the expression of Npt2a and Npt2c in the apical membrane. However, in contrast to PTH, FGF-23 downregulates the expression of the renal vitamin D 1- $\alpha$-hydroxylase and increases expression of the catabolic $25(\mathrm{OH}) \mathrm{D}$-24-hydroxylase, thus decreasing circulating $1,25(\mathrm{OH})_{2}$ vitamin D concentrations (Figure 1) [35]. In mice, increased dietary phosphate increases serum phosphate concentrations and circulating FGF-23, and the reciprocal relationship is consistent for low phosphate diets [38]. These relationships have also been reported in some human studies, but the effect of phosphate on FGF-23 appears to be less robust than in the animal studies [39-41]. Whether phosphate has direct effects on the skeleton to control FGF-23 production and secretion is currently unknown (Figure 1). Furthermore, patients with chronic kidney disease develop hyperphosphatemia, and FGF-23 is upregulated in these patients. This increase of FGF-23 may also be a response to the prevailing hyperphosphatemia, and has been associated with a five- to six-fold increase in mortality [42]. Increased FGF-23 is associated with reduced $1,25(\mathrm{OH})_{2}$ vitamin D concentrations [43], and a reduction in FGF-23 production most likely increases $1,25(\mathrm{OH})_{2}$ vitamin $\mathrm{D}$ through release of FGF-23-mediated 1- $\alpha$-hydroxylase suppression [44]. Recent evidence also points to a role for FGF-23 in directly regulating PTH production (Figure 1), as the FGF-23 core-ceptor Klotho is highly expressed in the parathyroid glands [45]. In this regard, FGF-23 delivery to bovine parathyroid cells in vitro or to rats in vivo increases p-ERK1/2 activity and reduces PTH mRNA and circulating concentrations, respectively $[46,47]$. The potential role of FGF-23 in the suppression of PTH in TIO remains to be determined, since the hypophosphatemia induced by elevated FGF-23 may also suppress PTH production in this disorder. Finally, other minerals, such as iron, have recently been implicated in humans to alter FGF-23 expression, which resulted in similar manifestations to TIO, including hypophosphatemia and osteomalacia [48].

Mouse models have provided critical insight into the function and mechanisms of FGF-23 activity. The transgenic over-expression of FGF-23 results in marked hypophosphatemia [49, 50]. High circulating FGF-23 concentrations in these animals leads to renal phosphate wasting through the down-regulation of Npt2a and Npt2c, which markedly increases phosphate excretion [49,50]. As expected, the transgenic mice have rickets/osteomalacia $[49,50]$, similar 
to patients with XLH, ADHR and TIO. The FGF-23-null mouse has the reciprocal phosphate phenotype to the FGF-23 transgenic mice, with severe hyperphosphatemia and elevated 1,25 $(\mathrm{OH})_{2}$ vitamin D resulting in soft-tissue calcifications, growth retardation, abnormal bone mineralization and decreased life expectancy [51,52]. Taken together, these findings indicate that FGF-23 regulates renal phosphate homeostasis by controlling renal reabsorption through regulation of the expression of the sodium dependent phosphate cotransporter family members, and vitamin D through control of the 1- $\alpha$-hydroxy-lase and the $25(\mathrm{OH}) \mathrm{D}$-24-hydroxylase.

Although FGF-23 regulation of Npt2a and Npt2c in the PT is well established, the molecular and cellular mechanisms whereby FGF-23 exerts its biological effects within the kidney remain largely unknown.

\section{Renal FGF-23 activity}

The coreceptor $\alpha$-Klotho (KL) was recently identified as necessary for FGF-23 bioactivity [53]. $\mathrm{KL}$ is produced as two isoforms due to alternative splicing of the same five-exon gene. Membrane bound $\mathrm{KL}$ (mKL) is a $130-\mathrm{kD}$ single-pass transmembrane protein comprised of all five exons, and is characterized by a large extracellular domain, with a short cytoplasmic region of 11 residues that does not contain signaling motifs [54]. The secreted form of KL is $80 \mathrm{kD}$ and is alternatively spliced within exon 3, producing a KL protein species that possesses the extracellular region, but not the transmembrane domain, and is secreted into the circulation [54]. A third isoform is produced by cleavage of $\mathrm{mKL}$ in proximity to the extracellular face of the plasma membrane, referred to as 'cut $\mathrm{mKL}$ ', resulting in a protein that is also found in the circulation [55]. The circulating forms of KL have led to interpretations that KL itself may act as a hormone [55].

In vitro evidence supports associations between FGF receptor-1c and KL as part of a receptor complex to elicit FGF-23 signaling through the MAPK cascade and phospho-ERK1/2 (pERK1/2) [53]. Interactions with multiple FGFRs and KL have also been identified [56]. Underlying the importance of the formation of a KL-FGFR receptor complex, high levels of FGF-23 signaling in vitro occur when KL and FGFR1c are coexpressed [53]. In support of FGF-23-KL interactions, the $F G F-23$ - and $K L$-null animals have identical hyperphosphatemic phenotypes $[45,51,52,57]$. Furthermore, a recessive, loss of function mutation in the human $K L$ gene resulted in impaired KL expression and activity, and to a severe tumoral calcinosis phenotype, most likely due to end-organ resistance to FGF-23 [58]. Although it has been shown that KL permits FGF-23 signaling in vitro, the mechanisms underlying FGF-23 bioactivity in the kidney are unclear, as KL localizes to the distal convoluted tubule (DCT) and FGF-23 mediates its effects on Npt2a, Npt2c and vitamin D metabolizing enzymes within the PT [35, 49]. We recently demonstrated that initial FGF-23 activity (5-10 min), as tested through detection of phospho-ERK1/2, occurs in the renal DCT, and was not localized with Npt2a in the renal PT [59]. Future studies are required to address the mechanisms underlying this DCTPT axis for FGF-23 bioactivity, and could reveal novel therapeutic targets for TIO and the heritable hypophosphatemias.

\section{FGF-23 half-life assessment in TIO}

The half-life of full length, active FGF-23 was determined through observations of serum FGF-23 levels before and following tumor resection in two TIO patients. As expected, FGF-23 was significantly elevated before surgery, and fell dramatically after the TIO lesion was removed, as assessed by the 'intact' ELISA [33]. Based upon the data from these two patients, the half-life of FGF-23 is estimated to be between $20-50 \mathrm{~min}[60,61]$. 


\section{Other genes highly expressed in tumors that cause TIO}

Expression studies performed on TIO tumors have revealed other candidate genes that have been described as potential phosphatonins. These include matrix extracellular phosphoglycoprotein (MEPE), Frizzled-related protein (FRP4), and FGF-7 [62-64]. Although increased expression of MEPE and FRP4 mRNA has been documented in multiple TIO tumors [36], their role in TIO and in phosphate regulation remains largely unclear. MEPE was first identified in tumor medium and osteosarcoma cell lines using polyclonal antibodies raised against the pre-operative serum from a TIO patient [62]. MEPE is predominantly expressed in odonto-blasts and osteocytes embedded in the mineralized matrix $[65,66]$. In vitro studies of human osteoblast cell cultures indicate that $M E P E$ expression is highest during the mineralization phase [67]. These data point to the possibility that MEPE may not regulate serum phosphate levels, but rather its expression could be directly or indirectly influenced by serum phosphate levels. Importantly, overproduction of MEPE by TIO tumors may directly reduce bone mineralization through the bioactivity of MEPE fragments within the skeleton [68].

FRP4 is a secreted member of the Frizzled protein family, and contains a cysteine-rich ligandbinding domain as well as a hydrophilic C-terminal region [63,69,70]. As with FGF-23 and MEPE, FRP4 was identified as one of the genes overexpressed in TIO tumors by SAGE analysis [36,71]. Studies have shown that FRP4 inhibits sodium-dependent phosphate uptake in opossum kidney (OK) cells in vitro [71]. Intravenous delivery of FRP4 $(0.3 \mu \mathrm{g} / \mathrm{kg} / \mathrm{h})$ to normal or parathyroidectomized mice was shown to cause hypophosphatemia secondary to increased phosphate excretion. These findings indicate that FRP4 may inhibit renal phosphate reabsorption independent of the regulating affects of PTH [71]. Altered regulation of Wnt signaling has been shown to promote tumor development and may be the reason for FRP4 over expression in TIO tumors [72-74]. Further studies are required to understand the role of FRP4 in phosphate handling and the altered bone mineralization in TIO.

Using a screen of TIO tumors that differentially inhibited phosphate transport in vitro, testing of identified candidates revealed that FGF-7 was an inhibitor of phosphate uptake in the OK cell line [64]. A neutralizing monoclonal antibody to FGF-7 reversed FGF-7-dependent phosphate transport inhibition and inhibitory activity in conditioned medium from tumor cell cultures. Immunoassays also revealed that FGF-7 was highly present in inhibitory conditioned medium and only in minimal amounts in non-conditioned medium or in conditioned medium with no phosphate transport inhibitory activity [64]. Expansion of these findings through FGF-7 delivery in vivo, as well as clinical studies examining FGF-7 levels in TIO patients before and after tumor resection, will be necessary to provide further insight into the role of FGF-7 in TIO.

The molecular mechanisms for the upregulation of these genes, and others, in tumors that cause TIO are unknown. Interestingly, TIO tumors may manifest an 'osteoblast/osteocyte' phenotype and overexpress genes such as DMPI and PHEX, in addition to MEPE and FGF-23. Recently, it has been suggested that ARHR caused by DMPI loss-of-function mutations may be a phenocopy of XLH [75,76]. The Dmpl-null mouse has an osteoblast to osteocyte transition defect where genes expressed in osteoblasts, such as alkaline phosphatase and type I collagen, as well as $F G F-23$, remained transcriptionally active and were markedly over-expressed in mature, embedded osteocytes [75]. Whether there is overlap in the differentiation defect that leads to TIO and the expression of DMPI, MEPE, PHEX and FGF-23, and the defect in ARHR (and possibly $\mathrm{XLH}$ ) is unknown. However, this may represent another crossover point, similar to the discovery of FGF-23 through different experimental approaches, where the acquired and heritable disorders of phosphate handling influence the understanding of each other. 


\section{Expert commentary}

In general, the TIO field currently relies on the biochemical phenotype of hypophosphatemia with inappropriately normal or low $1,25(\mathrm{OH})_{2}$ vitamin $\mathrm{D}$ in combination with the detection of elevated FGF-23 by ELISA, and imaging approaches as key indicators to make a general diagnosis [77]. However, the overlap of clinical symptoms with genetic and environmental causes of hypophosphatemia can make certain diagnosis difficult unless a neoplasm is detected and removed, and the clinical manifestations cease. A careful family history is still important in suspected TIO cases to rule out XLH, ADHR, and ARHR. XLH is completely penetrant, and the heritability patterns are well defined, thus, there is less of a concern with differential diagnosis unless it is a spontaneous PHEX mutation. ADHR has variable penetrance, and symptoms can appear and disappear in correlation with serum FGF-23 levels [78], thus this disorder may also resemble TIO. ARHR may affect one individual in a particular generation [75,76], therefore genetic testing for $F G F-23$ and $D M P 1$ mutations, respectively, in these cases may rule in a genetic cause. The $F G F-23$ mutations that result in ADHR are heterozygous and have all been at positions R176 or R179 within the subtilisin-like proprotein convertase RXXR/ $S$ cleavage site, making mutation assessment relatively straightforward [28]. However, in ARHR, if a mutation in DMP1 is not found, this still may not completely rule out ARHR, as intronic mutations and deletions that result in loss of function can be difficult to detect [76, 79].

\section{Five-year view}

Although TIO is certainly a rare disorder, the field could evolve over the next 5 years in the areas of tumor detection, and in new treatments for the reduced serum phosphate until the tumor is localized. For tumor detection, now that profiles of genes highly expressed by the tumors have been confirmed speculatively, identification of a cell-surface marker for an antibodybased detection system could potentially be developed. For treatment, humanized FGF-23neutralizing antibodies are currently in clinical trials for XLH therapy. These monoclonal antibodies reduce FGF-23 bioactivity in vitro and in vivo through interference with FGF-23FGFR and FGF-23-Klotho binding [80], and reverse the hypophosphatemia and skeletal manifestations associated with increased FGF-23 in the XLH mouse model, Hyp [81]. Ameliorating the symptoms of TIO by using the anti-FGF-23 antibodies until the tumor is found could alleviate potentially harmful effects of long-term phosphate and vitamin D therapy, including hyperparathyroidism and nephrocalcinosis with resulting renal insufficiency.

\section{Key issues}

- Tumor-induced osteomalacia (TIO) is a rare disorder that can be challenging to diagnose.

- TIO resembles heritable hypophosphatemias, therefore genetic testing may suggest a known disorder of phosphate wasting.

- TIO tumor localization can be difficult, and a strategy of combined imaging approaches may decrease the time between symptom onset and tumor isolation.

- FGF-23 is elevated in TIO and can be used as a marker for tumor identification.

- TIO has revealed novel aspects of endocrine interactions between the skeleton and the kidney, however it is not known why specific genes are up regulated in TIO tumors, and if this is related to the differentiation defect observed in some heritable hypophosphatemias. 
- Future developments in the field should focus on enhancing detection capabilities, as well as improved therapies for amelioration of the clinical manifestations of TIO, until a tumor can be identified.

\section{Acknowledgments}

We acknowledge the editorial and scientific contributions of Lelia Summers.

\section{References}

1. Econs MJ, Drezner MK. Tumor-induced osteomalacia - unveiling a new hormone. N Engl J Med 1994;330(23):1679-1681. [PubMed: 8177274]

2. Cai Q, Hodgson SF, Kao PC, et al. Brief report: inhibition of renal phosphate transport by a tumor product in a patient with oncogenic osteomalacia. N Engl J Med 1994;330(23):1645-1649. [PubMed: 8177270]

3. Ryan EA, Reiss E. Oncogenous osteomalacia. Review of the world literature of 2 cases and report of two new cases. Am J Med 1984;77(3):501-512. [PubMed: 6548080]

4. Imel EA, Peacock M, Pitukcheewanont $P$, et al. Sensitivity of fibroblast growth factor 3 measurements in tumor-induced osteomalacia. J Clin Endocrinol Metab 2006;91(6):2055-2061. [PubMed: 16551733]

5. Firth RG, Grant CS, Riggs BL. Development of hypercalcemic hyperparathyroidism after long-term phosphate supplementation in hypophosphatemic osteomalacia. Report of two cases. Am J Med 1985;78(4):669-673. [PubMed: 2984933]

6. Edelson GW, Shih MS, Parfitt AM. A unique case of adult hypophosphatemic osteomalacia. Bone 1993;14(5):707-710. [PubMed: 8268043]

7. Drezner, M. Tumor-induced rickets and osteomalacia. In: Favus, MJ., editor. Primer on the Metabolic Bone Disease and Disorders of Mineral Metabolism. Raven Press; NY, USA: 1996. p. 319-325.

8. Schapira D, Ben Izhak O, Nachtigal A, et al. Tumor-induced osteomalacia. Semin Arthritis Rheum 1995;25(1):35-46. [PubMed: 8525389]

9. Weidner N, Santa Cruz D. Phosphaturic mesenchymal tumors. A polymorphous group causing osteomalacia or rickets. Cancer 1987;59(8):1442-1454. [PubMed: 3545439]

10. Lorenz-Depiereux B, Benet-Pages A, Eckstein G, et al. Hereditary hypophosphatemic rickets with hypercalciuria is caused by mutations in the sodium-phosphate cotransporter gene SLC34A3. Am J Hum Genet 2006;78(2):193-201. [PubMed: 16358215]

11. Bergwitz C, Roslin NM, Tieder M, et al. SLC34A3 mutations in patients with hereditary hypophosphatemic rickets with hypercalciuria predict a key role for the sodium-phosphate cotransporter NaPi-IIc in maintaining phosphate homeostasis. Am J Hum Genet 2006;78(2):179192. [PubMed: 16358214]

12. Tieder M, Modai D, Shaked U, et al. "Idiopathic" hypercalciuria and hereditary hypophosphatemic rickets. Two phenotypical expressions of a common genetic defect. N Engl J Med 1987;316(3):125129. [PubMed: 3796683]

13. Folpe AL, Fanburg-Smith JC, Billings SD, et al. Most osteomalacia-associated mesenchymal tumors are a single histopathologic entity: an analysis of 2 cases and a comprehensive review of the literature. Am J Surg Pathol 2004;28(1):1-30. [PubMed: 14707860]

14. Fukumoto S, Takeuchi Y, Nagano A, Fujita T. Diagnostic utility of magnetic resonance imaging skeletal survey in a patient with oncogenic osteomalacia. Bone 1999;25(3):375-377. [PubMed: 10495143]

15. Hodgson SF, Clarke BL, Tebben PJ, Mullan BP, Cooney WP 3rd, Shives TC. Oncogenic osteomalacia: localization of underlying peripheral mesenchymal tumors with use of Tc $99 \mathrm{~m}$ sestamibi scintigraphy. Endocr Pract 2006;12(1):35-42. [PubMed: 16524861]

16. Kimizuka T, Ozaki Y, Sumi Y. Usefulness of $201 \mathrm{Tl}$ and 99mTc MIBI scintigraphy in a case of oncogenic osteomalacia. Ann Nucl Med 2004;18(1):63-67. [PubMed: 15072186]

17. Jan de Beur SM, Streeten EA, Civelek AC, et al. Localisation of mesenchymal tumours by somatostatin receptor imaging. Lancet 2002;359(9308):761-763. [PubMed: 11888589]

Expert Rev Endocrinol Metab. Author manuscript; available in PMC 2010 July 1. 
18. Seufert J, Ebert K, Muller J, et al. Octreotide therapy for tumor-induced osteomalacia. N Engl J Med 2001;345(26):1883-1888. [PubMed: 11756579]

19. Duet M, Kerkeni S, Sfar R, Bazille C, Liote F, Orcel P. Clinical impact of somatostatin receptor scintigraphy in the management of tumor-induced osteomalacia. Clin Nucl Med 2008;33(11):752756. [PubMed: 18936605]

20. Nasu T, Kurisu S, Matsuno S, et al. Tumor-induced hypophosphatemic osteomalacia diagnosed by the combinatory procedures of magnetic resonance imaging and venous sampling for FGF23. Intern Med 2008;47(10):957-961. [PubMed: 18480582]

21. van Boekel G, Ruinemans-Koerts J, Joosten F, Dijkhuizen P, van Sorge A, de Boer H. Tumor producing fibroblast growth factor 3 localized by two-staged venous sampling. Eur J Endocrinol 2008;158(3):431-437. [PubMed: 18299479]

22. Westerberg PA, Olauson H, Toss G, et al. Preoperative tumor localization by means of venous sampling for fibroblast growth factor-23 in a patient with tumor-induced osteomalacia. Endocr Pract 2008;14(3):362-367. [PubMed: 18463045]

23. Hesse E, Moessinger E, Rosenthal H, et al. Oncogenic osteomalacia: exact tumor localization by coregistration of positron emission and computed tomography. J Bone Miner Res 2007;22(1):158-162. [PubMed: 17014386]

24. Roarke MC, Nguyen BD. PET/CT localization of phosphaturic mesenchymal neoplasm causing tumor-induced osteomalacia. Clin Nucl Med 2007;32(4):300-301. [PubMed: 17413579]

25. Khadgawat R, Singh Y, Kansara S, et al. PET/CT localisation of a scapular haemangiopericytoma with tumour-induced osteomalacia. Singapore Med J 2009;50(2):e55-e57. [PubMed: 19296011]

26. Mannstadt M, Lorente C, Juppner H. Rapid detection of intact FGF-23 in tumor tissue from patients with oncogenic osteomalacia. Clin Chem 2008;54(7):1252-1254. [PubMed: 18593970]

27. Chalew SA, Lovchik JC, Brown CM, Sun CC. Hypophosphatemia induced in mice by transplantation of a tumor-derived cell line from a patient with oncogenic rickets. J Pediatr Endocrinol Metab 1996;9 (6):593-597. [PubMed: 9004174]

28. ADHR-Consortium. Autosomal dominant hypophosphataemic rickets is associated with mutations in FGF23. Nat Genet 2000;26(3):345-348. [PubMed: 11062477]

29. Shimada T, Muto T, Urakawa I, et al. Mutant FGF-23 responsible for autosomal dominant hypophosphatemic rickets is resistant to proteolytic cleavage and causes hypophosphatemia in vivo. Endocrinology 2002;143(8):3179-3182. [PubMed: 12130585]

30. White KE, Carn G, Lorenz-Depiereux B, Benet-Pages A, Strom TM, Econs MJ. Autosomal-dominant hypophosphatemic rickets (ADHR) mutations stabilize FGF-23. Kidney Int 2001;60(6):2079-2086. [PubMed: 11737582]

31. Riminucci M, Collins MT, Fedarko NS, et al. FGF-23 in fibrous dysplasia of bone and its relationship to renal phosphate wasting. J Clin Invest 2003;112(5):683-692. [PubMed: 12952917]

32. Jonsson KB, Zahradnik R, Larsson T, et al. Fibroblast growth factor 3 in oncogenic osteomalacia and X-linked hypophosphatemia. N Engl J Med 2003;348(17):1656-1663. [PubMed: 12711740]

33. Yamazaki Y, Okazaki R, Shibata M, et al. Increased circulatory level of biologically active full-length FGF-23 in patients with hypophosphatemic rickets/osteomalacia. J Clin Endocrinol Metab 2002;87 (11):4957-4960. [PubMed: 12414858]

34. White KE, Jonsson KB, Carn G, et al. The autosomal dominant hypophosphatemic rickets (ADHR) gene is a secreted polypeptide overexpressed by tumors that cause phosphate wasting. J Clin Endocrinol Metab 2001;86(2):497-500. [PubMed: 11157998]

35. Shimada T, Mizutani S, Muto T, et al. Cloning and characterization of FGF23 as a causative factor of tumor-induced osteomalacia. Proc Natl Acad Sci USA 2001;98(11):6500-6505. [PubMed: 11344269]

36. Jan De Beur SM, Finnegan RB, Vassiliadis J, et al. Tumors associated with oncogenic osteomalacia express genes important in bone and mineral metabolism. J Bone Miner Res 2002;17(6):1102-1110. [PubMed: 12054166]

37. Larsson T, Zahradnik R, Lavigne J, Ljunggren O, Juppner H, Jonsson KB. Immunohistochemical detection of FGF-23 protein in tumors that cause oncogenic osteomalacia. Eur J Endocrinol 2003;148 (2):269-276. [PubMed: 12590648] 
38. Perwad F, Azam N, Zhang MY, Yamashita T, Tenenhouse HS, Portale AA. Dietary and serum phosphorus regulate fibroblast growth factor 3 expression and 1,25-dihydroxyvitamin D metabolism in mice. Endocrinology 2005;146(12):5358-5364. [PubMed: 16123154]

39. Antoniucci DM, Yamashita T, Portale AA. Dietary phosphorus regulates serum fibroblast growth factor-23 concentrations in healthy men. J Clin Endocrinol Metab 2006;91(8):3144-3149. [PubMed: 16735491]

40. Nishida Y, Taketani Y, Yamanaka-Okumura H, et al. Acute effect of oral phosphate loading on serum fibroblast growth factor 3 levels in healthy men. Kidney Int 2006;70(12):2141-2147. [PubMed: 17063170]

41. Ito N, Fukumoto S, Takeuchi Y, et al. Effect of acute changes of serum phosphate on fibroblast growth factor (FGF)23 levels in humans. J Bone Miner Metab 2007;25(6):419-422. [PubMed: 17968495]

42. Gutierrez OM, Mannstadt M, Isakova T, et al. Fibroblast growth factor 3 and mortality among patients undergoing hemodialysis. N Engl J Med 2008;359(6):584-592. [PubMed: 18687639]

43. Shimada T, Hasegawa H, Yamazaki Y, et al. FGF-23 is a potent regulator of vitamin D metabolism and phosphate homeostasis. J Bone Miner Res 2004;19(3):429-435. [PubMed: 15040831]

44. Hesse M, Frohlich LF, Zeitz U, Lanske B, Erben RG. Ablation of vitamin D signaling rescues bone, mineral, and glucose homeostasis in Fgf-23 deficient mice. Matrix Biol 2007;26(2):75-84. [PubMed: 17123805]

45. Kuro-o M, Matsumura Y, Aizawa H, et al. Mutation of the mouse klotho gene leads to a syndrome resembling ageing. Nature 1997;390(6655):45-51. [PubMed: 9363890]

46. Krajisnik T, Bjorklund P, Marsell R, et al. Fibroblast growth factor-23 regulates parathyroid hormone and $1 \alpha$-hydroxylase expression in cultured bovine parathyroid cells. J Endocrinol 2007;195(1):125131. [PubMed: 17911404]

47. Ben-Dov IZ, Galitzer H, Lavi-Moshayoff V, et al. The parathyroid is a target organ for FGF23 in rats. J Clin Invest 2007;117(12):4003-4008. [PubMed: 17992255]

48. Schouten BJ, Hunt PJ, Livesey JH, Frampton CM, Soule SG. FGF23 elevation and hypophosphataemia following intravenous iron polymaltose - a prospective study. J Clin Endocrinol Metab 2009;94(7):2332-2337. [PubMed: 19366850]

49. Larsson T, Marsell R, Schipani E, et al. Transgenic mice expressing fibroblast growth factor 3 under the control of the $\alpha 1$ (I) collagen promoter exhibit growth retardation, osteomalacia, and disturbed phosphate homeostasis. Endocrinology 2004;145(7):3087-3094. [PubMed: 14988389]

50. Shimada T, Urakawa I, Yamazaki Y, et al. FGF-23 transgenic mice demonstrate hypophosphatemic rickets with reduced expression of sodium phosphate cotransporter type IIa. Biochem Biophys Res Comm 2004;314(2):409-414. [PubMed: 14733920]

51. Shimada T, Kakitani M, Yamazaki Y, et al. Targeted ablation of Fgf23 demonstrates an essential physiological role of FGF23 in phosphate and vitamin D metabolism. J Clin Invest 2004;113(4):561568. [PubMed: 14966565]

52. Sitara D, Razzaque MS, Hesse M, et al. Homozygous ablation of fibroblast growth factor-23 results in hyperphosphatemia and impaired skeletogenesis, and reverses hypophosphatemia in Phexdeficient mice. Matrix Biol 2004;23(7):421-432. [PubMed: 15579309]

53. Urakawa I, Yamazaki Y, Shimada T, et al. Klotho converts canonical FGF receptor into a specific receptor for FGF23. Nature 2006;444(7120):770-774. [PubMed: 17086194]

54. Matsumura Y, Aizawa H, Shiraki-Iida T, Nagai R, Kuro-o M, Nabeshima Y. Identification of the human klotho gene and its two transcripts encoding membrane and secreted klotho protein. Biochem Biophys Res Commun 1998;242(3):626-630. [PubMed: 9464267]

55. Imura A, Iwano A, Tohyama O, et al. Secreted Klotho protein in sera and CSF: implication for posttranslational cleavage in release of Klotho protein from cell membrane. FEBS Lett 2004;565(1-3): 143-147. [PubMed: 15135068]

56. Kurosu H, Ogawa Y, Miyoshi M, et al. Regulation of fibroblast growth factor-23 signaling by klotho. J Biol Chem 2006;281(10):6120-6123. [PubMed: 16436388]

57. Segawa H, Yamanaka S, Ohno Y, et al. Correlation between hyperphosphatemia and type II Na-Pi cotransporter activity in klotho mice. Am J Physiol Renal Physiol 2007;292(2):F769-F779.

[PubMed: 16985213] 
58. Ichikawa S, Imel EA, Kreiter ML, et al. A homozygous missense mutation in human KLOTHO causes severe tumoral calcinosis. J Clin Invest 2007;117(9):2684-2691. [PubMed: 17710231]

59. Farrow EG, Davis SI, Summers LJ, White KE. Initial FGF23-mediated signaling occurs in the distal convoluted tubule. J Am Soc Nephrol 2009;20(5):955-960. [PubMed: 19357251]

60. Khosravi A, Cutler CM, Kelly MH, et al. Determination of the elimination half-life of fibroblast growth factor-23. J Clin Endocrinol Metab 2007;92(6):2374-2377. [PubMed: 17374707]

61. Takeuchi Y, Suzuki H, Ogura S, et al. Venous sampling for fibroblast growth factor-23 confirms preoperative diagnosis of tumor-induced osteomalacia. J Clin Endocrinol Metab 2004;89(8):39793982. [PubMed: 15292336]

62. Rowe PS, de Zoysa PA, Dong R, et al. MEPE, a new gene expressed in bone marrow and tumors causing osteomalacia. Genomics 2000;67(1):54-68. [PubMed: 10945470]

63. Berndt T, Craig TA, Bowe AE, et al. Secreted frizzled-related protein 4 is a potent tumor-derived phosphaturic agent. J Clin Invest 2003;112(5):785-794. [PubMed: 12952927]

64. Carpenter TO, Ellis BK, Insogna KL, Philbrick WM, Sterpka J, Shimkets R. Fibroblast growth factor 7: an inhibitor of phosphate transport derived from oncogenic osteomalacia-causing tumors. J Clin Endocrinol Metab 2005;90(2):1012-1020. [PubMed: 15562028]

65. Lu C, Huang S, Miclau T, Helms JA, Colnot C. Mepe is expressed during skeletal development and regeneration. Histochem Cell Biol 2004;121(6):493-499. [PubMed: 15221418]

66. Nampei A, Hashimoto J, Hayashida K, et al. Matrix extracellular phosphoglycoprotein (MEPE) is highly expressed in osteocytes in human bone. J Bone Miner Metab 2004;22(3):176-184. [PubMed: 15108058]

67. Siggelkow H, Schmidt E, Hennies B, Hufner M. Evidence of downregulation of matrix extracellular phosphoglycoprotein during terminal differentiation in human osteoblasts. Bone 2004;35(2):570576. [PubMed: 15268910]

68. Rowe PS, Kumagai Y, Gutierrez G, et al. MEPE has the properties of an osteoblastic phosphatonin and minhibin. Bone 2004;34(2):303-319. [PubMed: 14962809]

69. Jones SE, Jomary C. Secreted Frizzled-related proteins: searching for relationships and patterns. Bioessays 2002;24(9):811-820. [PubMed: 12210517]

70. Rattner A, Hsieh JC, Smallwood PM, et al. A family of secreted proteins contains homology to the cysteine-rich ligand-binding domain of frizzled receptors. Proc Natl Acad Sci USA 1997;94(7): 2859-2863. [PubMed: 9096311]

71. Berndt T, Craig TA, Bowe AE, et al. Secreted frizzled-related protein 4 is a potent tumor-derived phosphaturic agent. J Clin Invest 2003;112(5):785-794. [PubMed: 12952927]

72. Kurose K, Sakaguchi M, Nasu Y, et al. Decreased expression of REIC/Dkk-3 in human renal clear cell carcinoma. J Urol 2004;171(3):1314-1318. [PubMed: 14767340]

73. Nozaki I, Tsuji T, Iijima O, et al. Reduced expression of REIC/Dkk-3 gene in non-small cell lung cancer. Int J Oncol 2001;19(1):117-121. [PubMed: 11408931]

74. Tsuji T, Nozaki I, Miyazaki M, et al. Antiproliferative activity of REIC/Dkk-3 and its significant down-regulation in non-small-cell lung carcinomas. Biochem Biophys Res Commun 2001;289(1): 257-263. [PubMed: 11708809]

75. Feng JQ, Ward LM, Liu S, et al. Loss of DMP1 causes rickets and osteomalacia and identifies a role for osteocytes in mineral metabolism. Nat Genet 2006;38(11):1310-1315. [PubMed: 17033621]

76. Lorenz-Depiereux B, Bastepe M, Benet-Pages A, et al. DMP1 mutations in autosomal recessive hypophosphatemia implicate a bone matrix protein in the regulation of phosphate homeostasis. Nat Genet 2006;38(11):1248-1250. [PubMed: 17033625]

77. Endo I, Fukumoto S, Ozono K, et al. Clinical usefulness of measurement of fibroblast growth factor 23 (FGF23) in hypophosphatemic patients: proposal of diagnostic criteria using FGF23 measurement. Bone 2008;42(6):1235-1239. [PubMed: 18396126]

78. Imel EA, Hui SL, Econs MJ. FGF23 concentrations vary with disease status in autosomal dominant hypophosphatemic rickets. J Bone Miner Res 2007;22(4):520-526. [PubMed: 17227222]

79. Farrow EG, Davis SI, Ward LM, et al. Molecular analysis of DMP1 mutants causing autosomal recessive hypophosphatemic rickets. Bone 2009;44(2):287-294. [PubMed: 19007919] 
80. Yamazaki Y, Tamada T, Kasai N, et al. Anti-FGF23 neutralizing antibodies show the physiological role and structural features of FGF23. J Bone Miner Res 2008;23(9):1509-1518. [PubMed: 18442315]

81. Aono Y, Yamazaki Y, Yasutake J, et al. Therapeutic effects of anti-FGF23 antibodies in hypophosphatemic rickets/osteomalacia. J Bone Miner Res. 2009 


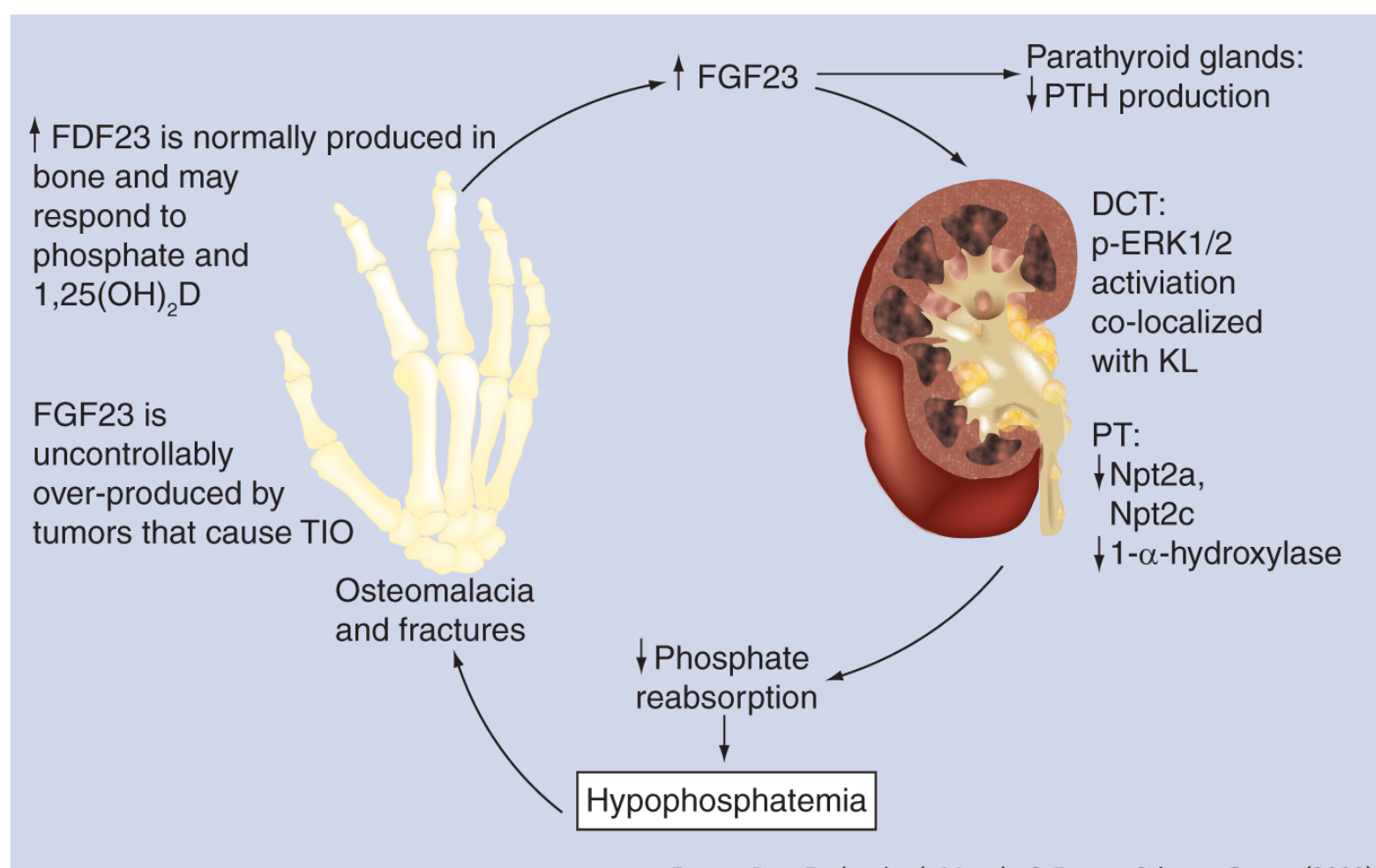

Expert Rev. Endocrinol. Metab. () Future Science Group (2009)

Figure 1. FGF-23 actions on phosphate metabolism

FGF-23 is normally produced by bone cells and secreted into the circulation, potentially in response to increased phosphate and/or $1,25(\mathrm{OH})_{2}$ vitamin D. In TIO, a tumor produces excess FGF-23. FGF-23 may initially act in the renal DCT, subsequently leading to a decrease in Npt2a and Npt2c expression and a decrease in $1,25(\mathrm{OH})_{2}$ vitamin D production in the PT. Ultimately, continuously elevated serum FGF-23 results in renal phosphate wasting and hypophosphatemia, followed by osteomalacia and fractures. FGF-23 reduces PTH mRNA and protein, however the role of this action of FGF-23 in TIO remains to be determined.

DCT: Distal convoluted tubule; Npt2: Type II sodium phosphate cotransporter; PT: Proximal tubule; PTH: Parathyroid hormone; TIO: Tumor-induced osteomalacia. 
Table 1

Heritable disorders of hypophosphatemia.

\begin{tabular}{|llll|}
\hline Disorder & Gene & Effect of mutation & $\begin{array}{l}\text { Effect on } \\
\text { FGF-23 }\end{array}$ \\
\hline X-linked hypophosphatemic rickets & $\begin{array}{l}\text { Phosphate-regulating gene with } \\
\text { homologies to endopeptidases on } \\
\text { the X-chromosome }\end{array}$ & Loss of function & $\uparrow$ \\
\hline $\begin{array}{l}\text { Autosomal dominant } \\
\text { hypophosphatemic rickets }\end{array}$ & FGF-23 & Gain of function & $\uparrow \leftrightarrow$ \\
\hline $\begin{array}{l}\text { Autosomal recessive hypophosphatemic } \\
\text { rickets }\end{array}$ & Dentin matrix protein-1 & Loss of function & $\uparrow$ \\
\hline $\begin{array}{l}\text { Hereditary hypophosphatemic rickets } \\
\text { with hypercalciuria }\end{array}$ & $\begin{array}{l}\text { Type IIc Sodium-phosphate } \\
\text { cotransporter (NPT2c; } \\
\text { SLC34A3) }\end{array}$ & Loss of function & $\downarrow$ \\
\hline
\end{tabular}

A detailed family history and biochemical evaluation is important for a correct tumor-induced osteomalacia diagnosis, as these listed disorders could resemble tumor-induced osteomalacia (hereditary hypophosphatemic rickets with hypercalciuria listed based upon hypophosphatemia alone).

$\leftrightarrow$ Unchanged concentration. 